\title{
Reduced Intravenous Fluorescein Dose for Upper and Lower Gastrointestinal Tract Probe-Based Confocal Laser Endomicroscopy
}

\author{
Kazuya Inoki ${ }^{1,2}$, Seiichiro Abe ${ }^{1}$, Yusaku Tanaka ${ }^{1,3}$, Koji Yamamoto ${ }^{1,4}$, Daisuke Hihara ${ }^{1,5}$, Ryoji Ichijima ${ }^{1,6}$, Yukihiro Nakatani ${ }^{1,7}$, Hsin- \\ Yu Chen ${ }^{1,8}$, Hiroyuki Takamaru', Masau Sekiguchi ${ }^{1,9}$, Masayoshi Yamada', Taku Sakamoto', Satoru Nonaka ${ }^{1}$, Haruhisa Suzuki ${ }^{1}$, \\ Shigetaka Yoshinaga ${ }^{1}$, Ichiro Oda', Takahisa Matsuda, ${ }^{1,9}$ and Yutaka Saito ${ }^{1}$ \\ ${ }^{1}$ Endoscopy Division, National Cancer Center Hospital, Tokyo, ${ }^{2}$ Division of Gastroenterology, Department of Medicine, Showa University \\ School of Medicine, Tokyo, ${ }^{3}$ Department of Gastroenterology, Keiyu Hospital, Kanagawa, ${ }^{4}$ Department of Gastroenterology, Arao \\ Municipal Hospital, Kumamoto, ${ }^{5}$ Division of Gastroenterology and Hepatology, Toho University Medical Center Ohashi Hospital, Tokyo, \\ ${ }^{6}$ Division of Gastroenterology and Hepatology, Department of Medicine, Nihon University School of Medicine, Tokyo, ${ }^{7}$ Department \\ of Gastroenterology, Chofu Touzan Hospital, Tokyo, Japan, ${ }^{8}$ Division of Gastroenterology, Cathay General Hospital, Taipei, Taiwan, \\ ${ }^{9}$ Cancer Screening Center, National Cancer Center Hospital, Tokyo, Japan
}

Background/Aims: Probe-based confocal laser endomicroscopy (pCLE) requires the administration of intravenous (IV) fluorescein. This study aimed to determine the optimal dose of IV fluorescein for both upper and lower gastrointestinal (GI) tract pCLE. Methods: Patients 20 to 79 years old with gastric high-grade dysplasia (HGD) or colorectal neoplasms (CRNs) were enrolled in the study. The dose de-escalation method was employed with five levels. The primary endpoint of the study was the determination of the optimal dose of IV fluorescein for pCLE of the GI tract. The reduced dose was determined based on off-line reviews by three endoscopists. An insufficient dose of fluorescein was defined as the dose of fluorescein with which the pCLE images were not deemed to be visible. If all three endoscopists determined that the tissue structure was visible, the doses were de-escalated. Results: A total of 12 patients with gastric HGD and 12 patients with CRNs were enrolled in the study. Doses were de-escalated to $0.5 \mathrm{mg} / \mathrm{kg}$ of fluorescein for both non-neoplastic duodenal and colorectal mucosa. All gastric HGD or CRNs were visible with pCLE with IV fluorescein at $0.5 \mathrm{mg} / \mathrm{kg}$.

Conclusions: In the present study, pCLE with IV fluorescein $0.5 \mathrm{mg} / \mathrm{kg}$ was adequate to visualize the magnified structure of both the upper and lower GI tract. Clin Endosc 2021;54:363-370

Key Words: Duodenum; Endoscopy; Fluorescein; Lower gastrointestinal tract; Stomach

\section{INTRODUCTION}

The development of probe-based confocal laser endomicroscopy (pCLE) has allowed endoscopists to observe gastrointestinal (GI) lesions with thousand-fold magnification and

Received: February 26, 2020 Revised: April 23, 2020

Accepted: April 24, 2020

Correspondence: Seiichiro Abe

Endoscopy Division, National Cancer Center Hospital, 5-1-1 Tsukiji, Chuo-ku, Tokyo 104-0045, Japan

Tel: +81-3-3542-2511, Fax: +81-3-3542-3815, E-mail: seabe@ncc.go.jp

ORCID: https://orcid.org/0000-0002-2736-6921

cc This is an Open Access article distributed under the terms of the Creative Commons Attribution Non-Commercial License (http://creativecommons.org/ licenses/by-nc/3.0) which permits unrestricted non-commercial use, distribution, and reproduction in any medium, provided the original work is properly cited. real time in vivo histologic evaluation of the lesions. ${ }^{1}$ Several prior studies have already shown the usefulness and safety of optical biopsy using pCLE in the field of gastroenterology ${ }^{2-5}$ and it has further been reported that pCLE is relatively easy to learn. ${ }^{6,7}$ Intravenous (IV) fluorescein is an essential contrast agent required to obtain clear images with pCLE. Although rare, severe adverse reactions to IV fluorescein, that may lead to life-threatening conditions, ${ }^{8-10}$ have been reported. Furthermore, the incidence of nausea and vomiting after IV administration of fluorescein has been reported to be as high as around $6 \%$ for nausea and $1 \%$ for vomiting. ${ }^{11-13}$ Ethnic variation has also reported for fluorescein induced nausea and vomiting, with a higher risk of occurrence in Asian individuals compared to Caucasian individuals. ${ }^{14}$ Moreover, a dose-dependent adverse reactions response for IV or intrathecally ad- 
ministered fluorescein has been reported. ${ }^{10,15}$ Typically, an IV dose of fluorescein used for GI pCLE is 250 or $500 \mathrm{mg}$ (roughly $4-8 \mathrm{mg} / \mathrm{kg}$ ) for fluorescein angiography. The optimal dose for IV fluorescein during pCLE is still controversial. Taking into consideration the dose-dependent risk of adverse events and the ethnic variation of fluorescein related reactions, such as fluorescein induced nausea, we investigated whether performing pCLE with a lower IV fluorescein dose compromises image quality in Asian patients.

The aim of this study is to investigate the optimal dose of IV fluorescein for pCLE of the upper and lower GI tract using non-neoplastic duodenal and colorectal mucosa.

\section{MATERIALS AND METHODS}

\section{Study design and patients}

This study was conducted between February and October in 2017 in a single center. The inclusion criteria were Japanese patients aged 20 to 79 with gastric high-grade dysplasia (HGD) or colorectal neoplasms (CRNs) scheduled for either endoscopic resection or surgery. Gastric HGD was diagnosed by biopsy while CRNs were diagnosed endoscopically. The major exclusion criteria were clinically significant medical conditions that could potentially affect study participation as determined by the investigator, including but not limited to the following conditions: (1) risk of biopsy or endoscopic resection due to comorbidities (e.g., hematological diseases), (2) inability to discontinue antithrombotic agents, (3) known allergies or hypersensitivity to fluorescein, (4) liver and/or kidney dysfunction (aspartate aminotransferase $>100 \mathrm{U} / \mathrm{L}$, alanine aminotransferase $>100 \mathrm{U} / \mathrm{L}$, serum creatinine $>1.5 \mathrm{mg} / \mathrm{dL}$ ), and (5) inflammatory bowel disease. The primary endpoint was the determination of the optimal dose of IV fluorescein for pCLE of the GI tract. Secondary endpoints were the visibility of the histological microstructure on the PCLE and the frequency of adverse reactions. The present study was conducted following the ethical guidelines of the 1975 Declaration of Helsinki, was approved by the institutional review board of National Cancer Center Hospital, Tokyo, Japan (2016-219), and was registered in the University Hospital Medical Information Network (UMIN) clinical trials registry (UMIN000027696). The number of target cases depended on the progress of the study, and there was an estimate of 12 to 24 cases. Written informed consent was obtained by all participants prior to protocol-specific examination procedures.

\section{Endoscopy equipment and pCLE procedure}

Each endoscopic procedure was performed with a high-definition gastroscope (GIF-H290Z; Olympus, Tokyo, Japan) or colonoscope (PCF-H290Z/I; Olympus). A black soft cap (MAJ-1989 or MAJ-1990; Olympus) was attached to the tip of the endoscope according to the endoscopist's preference. The pCLE device used for the present study was Gastro Flex UHD (Cellvizio; Mauna Kea Technologies, Paris, France) with a diameter of $2.6 \mathrm{~mm}$ and lateral resolution of $1 \mu \mathrm{m}$. The pCLE probe was attached to the mucosa vertically and it took around 10 seconds to observe each target lesion while determining a stable scope position with the use of a straight endoscopic cap.

\section{Study examination flow}

This study used a dose de-escalation method that has previously been used in a phase I clinical trial. ${ }^{16}$ An insufficient dose (ID) of fluorescein was defined as a dose with which the pCLE images were obscure or not visible. Five levels were set and the fluorescein dose of each level were $5 \mathrm{mg} / \mathrm{kg}, 4 \mathrm{mg} / \mathrm{kg}$,

Table 1. Decisions according to the Results of Each Level

\begin{tabular}{|c|c|c|c|}
\hline Level & Dose of IV fluorescein (mg/kg) & The number of ID in 3 cases & Decision \\
\hline \multirow[t]{2}{*}{5} & 5 & 0 & Optimal dose is level 5 \\
\hline & & $1 \leq$ & Difficult to reduce the dose of IV fluorescein \\
\hline \multirow[t]{2}{*}{4} & 4 (initial dose) & 0 & Go to level 3 \\
\hline & & $1 \leq$ & Go to level 5 \\
\hline \multirow[t]{2}{*}{3} & 2 & 0 & Go to level 2 \\
\hline & & $1 \leq$ & Optimal dose is level 4 \\
\hline \multirow[t]{2}{*}{2} & 1 & 0 & Go to level 1 \\
\hline & & $1 \leq$ & Optimal dose is level 3 \\
\hline \multirow[t]{2}{*}{1} & 0.5 (minimal dose) & 0 & Optimal dose is level 1 \\
\hline & & $1 \leq$ & Optimal dose is level 2 \\
\hline
\end{tabular}

ID, insufficient dose; IV, intravenous. 
$2 \mathrm{mg} / \mathrm{kg}, 1 \mathrm{mg} / \mathrm{kg}$, and $0.5 \mathrm{mg} / \mathrm{kg}$ (Table 1). Three cases were planned for each level. The planned initial dose of fluorescein was set as $4 \mathrm{mg} / \mathrm{kg}$ which was administered to three patients with gastric HGDs. The same method was adopted for patients with CRNs.

The flow of examination is shown in Fig. 1. All examinations were performed by expert endoscopists. An expert endoscopist was defined as a board certified fellow or trainer of the Japan Gastroenterological Endoscopy Society. Regarding the upper GI tract, for patients with the preoperative diagnosis of HGD, first we performed endoscopic examinations with white light imaging, chromoendoscopy with indigo carmine dye, and magnifying narrow band imaging (NBI). Next, the planned dose of IV fluorescein was administered and pCLE was performed by inserting the pCLE probe through the biopsy channel of the endoscope and gently positioning the probe in direct contact with the mucosa. Non-neoplastic mucosa of the duodenal bulb was observed at 30 seconds, 5 minutes, and 10 minutes after IV fluorescein administration. HGD was observed with pCLE between the intervals of pCLE examination of non-neoplastic duodenal mucosa. All pCLE examinations were video recorded.

Similarly, for the lower GI tract, we first performed preoperative examination including white light imaging, chromoendoscopy with indigo carmine dye, and magnifying NBI diagnosis according to the Japan NBI expert team (JNET) classification ${ }^{17}$ for CRNs. Next, the planned dose of IV fluorescein was administered and the pCLE probe was inserted through the biopsy channel of the endoscope and gently positioned in direct contact with the mucosa. Non-neoplastic colorectal mucosa close to the CRNs was observed at 30 seconds, 5 minutes, and 10 minutes after IV fluorescein. CRNs were observed with pCLE between the intervals of pCLE examination of non-neoplastic colorectal mucosa.

The blood pressure, heart rate, oxygen saturation, and respiratory rate for all enrolled patients were monitored during and after the procedure. Furthermore, at the time of the follow-up outpatient visit, 2 or 3 weeks after the endoscopic examination, we monitored the development of any adverse reactions and all patients were asked whether they had developed any known symptoms such as nausea, vomiting, itchiness, or yellowish urine after IV fluorescein administration.

\section{On-site diagnosis and off-line review}

On-site diagnosis of HGDs or CRNs was made by the endoscopists who performed the examination. The video of pCLE was reviewed off-line by three expert endoscopists (KI, SA and YS) to evaluate the visibility of tissue structure. Each expert reviewed the recorded videos independently and evaluated the visibility of the tissue structure by pCLE at the determined time intervals of 30 seconds, 5 minutes, and 10 minutes. They each judged the results as visible or invisible. The judgment of visibility was defined as a condition where the tissue structure by pCLE was visible according to the Miami classification. ${ }^{18}$ The judgment of invisibility was defined as a condition where the tissue structure by pCLE was obscure and difficult to interpret. Furthermore, the visibility of pCLE features of HGDs and CRNs were reviewed.
Study flow

A Esophagogastroduodenoscopy

IV fluorescein

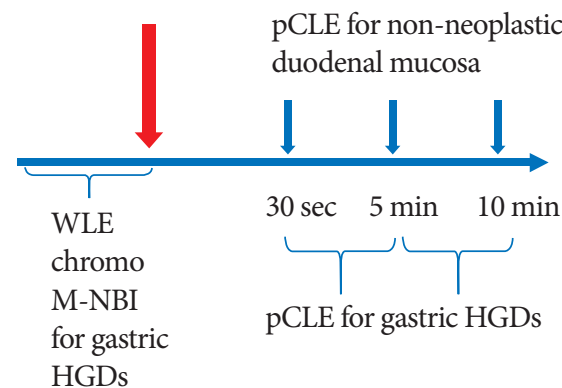

(B) Colonoscopy

IV fluorescein

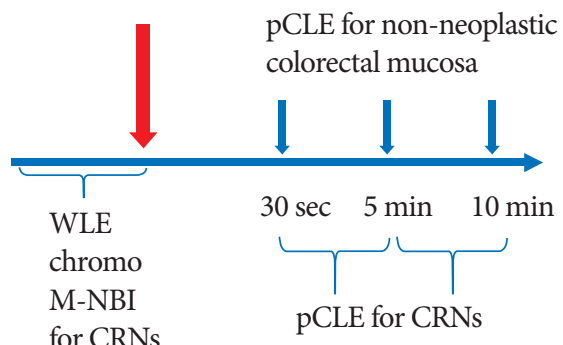

Fig. 1. The flow of the study for gastric high-grade dysplasia (HGD) and colorectal neoplasms (CRNs). The planned dose of fluorescein was administered after white light imaging, chromoendoscopy, and magnifying narrow band imaging (M-NBI) for (A) gastric HGD and (B) CRNs. Non-neoplastic duodenal mucosa or colorectal mucosa were observed at 30 seconds, 5 minutes, and 10 minutes with probe-based confocal laser endomicroscopy (pCLE). During the period between the times set for pCLE examination of non-neoplastic mucosa, HGDs and CRNs were observed with PCLE. IV, intravenous; WLE, white light endoscopy. 


\section{Dose de-escalation}

The dose was de-escalated to the next lower level if the tissue structure of all three cases were judged as visible by all reviewer endoscopists. An ID was defined as the dose where at least one of the three endoscopists judged that tissue structure was not visible in the off-line review at the timing of $10 \mathrm{~min}$ utes after IV fluorescein administration. The optimal dose was defined as the dose 1 level higher than ID. If the tissue structure of all three cases were judged as visible at level 1 , level 1 was defined as the optimal dose. The study flow of the dose de-escalation method used is summarized in Table 1.

Table 2. Lesion Characteristics of All Cases in the Present Study

\begin{tabular}{|c|c|}
\hline \multicolumn{2}{|l|}{ Upper GI tract } \\
\hline \multicolumn{2}{|l|}{ Location, $n$} \\
\hline Upper stomach & 4 \\
\hline Middle stomach & 4 \\
\hline Lower stomach & 4 \\
\hline Lesion size, median, mm (range) & $12(8-30)$ \\
\hline \multicolumn{2}{|l|}{ Macroscopic type, $n$} \\
\hline 0-IIb & 1 \\
\hline 0-IIc & 11 \\
\hline \multicolumn{2}{|l|}{ Ulcer, $n$} \\
\hline Present & 2 \\
\hline Absent & 10 \\
\hline \multicolumn{2}{|l|}{ Pathological findings, $n$} \\
\hline Differentiated type & 10 \\
\hline Undifferentiated type & 2 \\
\hline \multicolumn{2}{|l|}{ Lower GI tract } \\
\hline \multicolumn{2}{|l|}{ Location, $n$} \\
\hline Rectum & 3 \\
\hline Sigmoid colon & 2 \\
\hline Transvers colon & 3 \\
\hline Ascending colon & 4 \\
\hline Lesion size, median, mm (range) & $25(15-40)$ \\
\hline \multicolumn{2}{|l|}{ Macroscopic type, $n$} \\
\hline $0-\mathrm{I}$ & 1 \\
\hline 0-I+0-IIa & 2 \\
\hline 0-I+0-IIc & 1 \\
\hline 0-IIa & 6 \\
\hline 0-IIa+0-IIc & 1 \\
\hline 0 -IIc & 1 \\
\hline \multicolumn{2}{|l|}{ Pathological findings, $n$} \\
\hline Low grade dysplasia & 4 \\
\hline High grade dysplasia & 7 \\
\hline Sessile serrated adenoma/polyp & 1 \\
\hline
\end{tabular}

GI, gastrointestinal.

\section{RESULTS}

A total of 24 patients, 12 with gastric neoplasms and $12 \mathrm{pa}-$ tients with CRNs, were enrolled in this study. There were 11 men and one woman with gastric lesions, and four men and eight women with CRNs, respectively. The median age was 72 years (61-77) and 66 years (41-79), respectively. The lesion features in the present study are shown in Table 2.

For the upper GI tract, no ID was identified, and the dose was de-escalated to $0.5 \mathrm{mg} / \mathrm{kg}$ IV fluorescein (Table 3). The median weight of enrolled patients was $58 \mathrm{~kg}(46-80)$. The median administered fluorescein dose was $75 \mathrm{mg}$ (29-300). Furthermore, the tissue structure of all HGDs was observed successfully with pCLE at all dose levels. On-site pCLE diagnosis also revealed that it was possible to evaluate the surface structure of HGD at any level.

In regard to the lower GI tract, no ID was experienced either and the doses were de-escalated to $0.5 \mathrm{mg} / \mathrm{kg}$ IV fluorescein (Table 3). The median weight of enrolled patients was 51 $\mathrm{kg}$ (43-91). The median administered fluorescein dose was 84 $\mathrm{mg}$ (21-364). Further, the tissue structure of all CRNs was observed successfully with pCLE at all dose levels. On-site pCLE diagnosis also revealed that it was possible to evaluate the surface structure of $\mathrm{CRN}$ at any levels.

No adverse reactions were encountered with the 23 cases, with only one patient presenting with yellowish urine after level 4 IV fluorescein administration.

Table 3. Dose of the Fluorescein and Visibility of Tissue Structure in ProbeBased Confocal Laser Endomicroscopy

\begin{tabular}{|c|c|c|c|c|c|c|}
\hline \multirow[b]{2}{*}{ Level } & \multicolumn{3}{|c|}{$\begin{array}{l}\text { Non-neoplastic mucosa of } \\
\text { duodenal bulb }\end{array}$} & \multicolumn{3}{|c|}{$\begin{array}{c}\text { Non-neoplastic mucosa of } \\
\text { colorectal mucosa }\end{array}$} \\
\hline & $\begin{array}{l}\text { Weight } \\
\text { (kg) }\end{array}$ & $\begin{array}{l}\text { Dose } \\
\text { (mg/ } \\
\text { body) }\end{array}$ & Visibility & $\begin{array}{l}\text { Weight } \\
\text { (kg) }\end{array}$ & $\begin{array}{l}\text { Dose } \\
\text { (mg/ } \\
\text { body) }\end{array}$ & Visibility \\
\hline 4 & 76 & 300 & Visible & 47 & 188 & Visible \\
\hline 4 & 65 & 260 & Visible & 52 & 208 & Visible \\
\hline 4 & 53 & 212 & Visible & 91 & 364 & Visible \\
\hline 3 & 51 & 102 & Visible & 60 & 120 & Visible \\
\hline 3 & 80 & 160 & Visible & 67 & 134 & Visible \\
\hline 3 & 46 & 92 & Visible & 71 & 142 & Visible \\
\hline 2 & 52 & 52 & Visible & 44 & 44 & Visible \\
\hline 2 & 55 & 55 & Visible & 43 & 43 & Visible \\
\hline 2 & 58 & 58 & Visible & 47 & 47 & Visible \\
\hline 1 & 76 & 38 & Visible & 43 & 21 & Visible \\
\hline 1 & 59 & 29 & Visible & 66 & 33 & Visible \\
\hline 1 & 58 & 29 & Visible & 50 & 25 & Visible \\
\hline
\end{tabular}



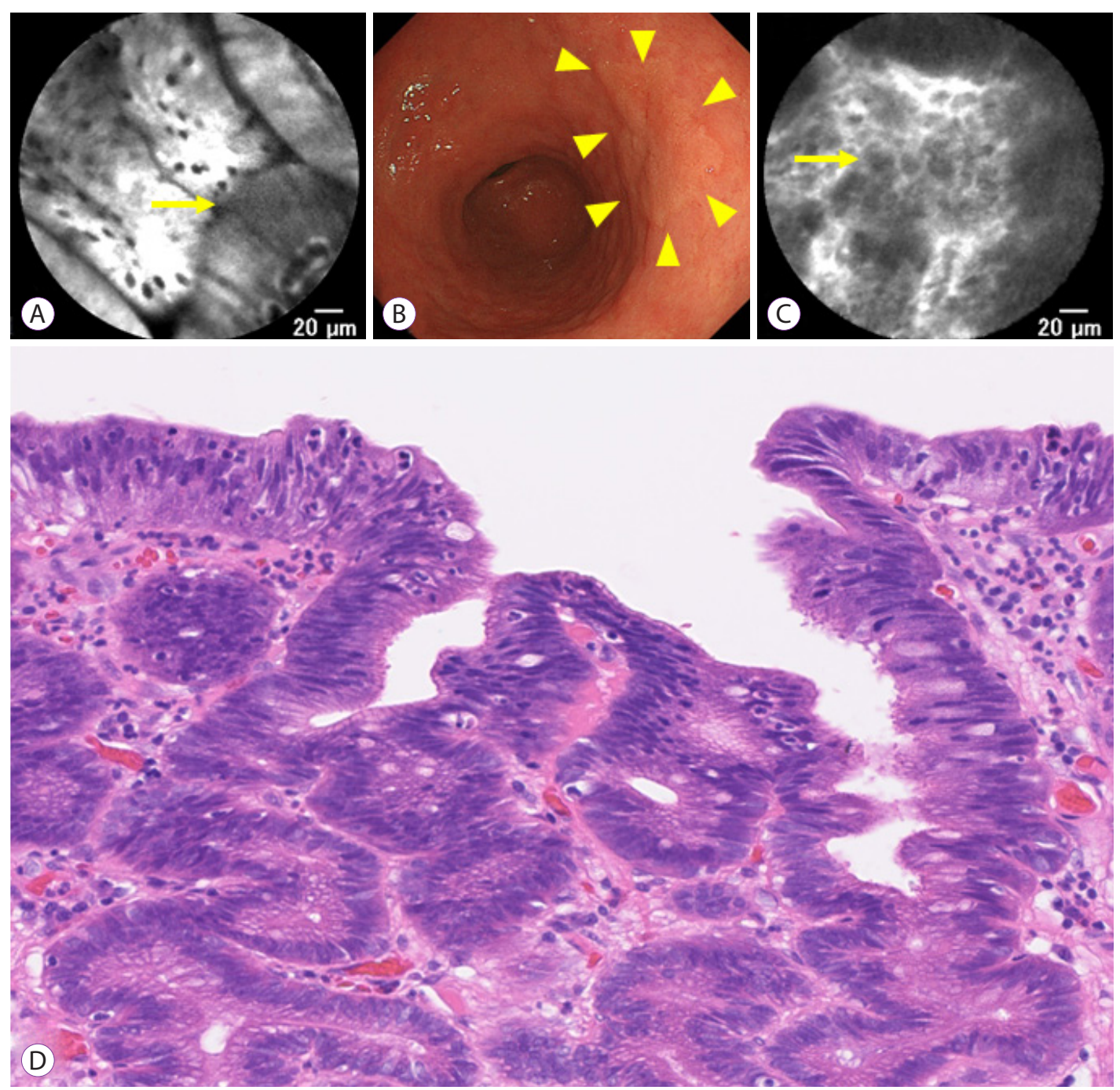

Fig. 2. A representative case of duodenal mucosa and gastric high-grade dysplasia (HGD) observed with probe-based confocal laser endomicroscopy (pCLE) with 0.5 $\mathrm{mg} / \mathrm{kg}$ of fluorescein. (A) Duodenal mucosa observed with pCLE, villiform architecture is seen (arrow), (B) gastric HGD located at the posterior wall of the antrum with white light imaging, (C) HGD observed with pCLE, dark irregular epithelium is seen (arrow), and (D) hematoxylin and eosin stain of HGD.

Fig. 2. shows a representative case of pCLE findings with 0.5 $\mathrm{mg} / \mathrm{kg}$ of IV fluorescein for the duodenal mucosa and gastric HGD. The duodenal glands were visible with PCLE at 10 minutes after IV fluorescein administration. The $22 \mathrm{~mm}$ gastric lesion with HGD was located at the posterior wall of the antrum, which was also visible with pCLE. Fig. 3. shows a representative case of pCLE findings with $0.5 \mathrm{mg} / \mathrm{kg}$ IV fluorescein for the non-neoplastic colon mucosa and a serrated lesion. The colonic glands were visible with pCLE at 10 minutes after IV fluorescein administration. The sessile serrated adenoma, located at the ascending colon, was also visible with pCLE.

\section{DISCUSSION}

Although pCLE for GI lesions is a useful modality which enables endoscopists to perform optical biopsy, IV fluorescein is necessary to visualize the micro surface and micro vessel structures. In the present study, we aimed to determine the optimal dose of pCLE for colorectal and duodenal mucosa. The dose of fluorescein was successfully de-escalated from the corresponding dose used during angiography to level 1 (the minimum dose), and only a small amount of fluorescein $(0.5$ $\mathrm{mg} / \mathrm{kg}$ ) was sufficient to visualize the non-neoplastic duodenal and colorectal mucosa features. Furthermore, all target lesions were also visible by pCLE with the minimal dose at $10 \mathrm{~min}$ utes, thus it was considered feasible to perform a pretreatment 

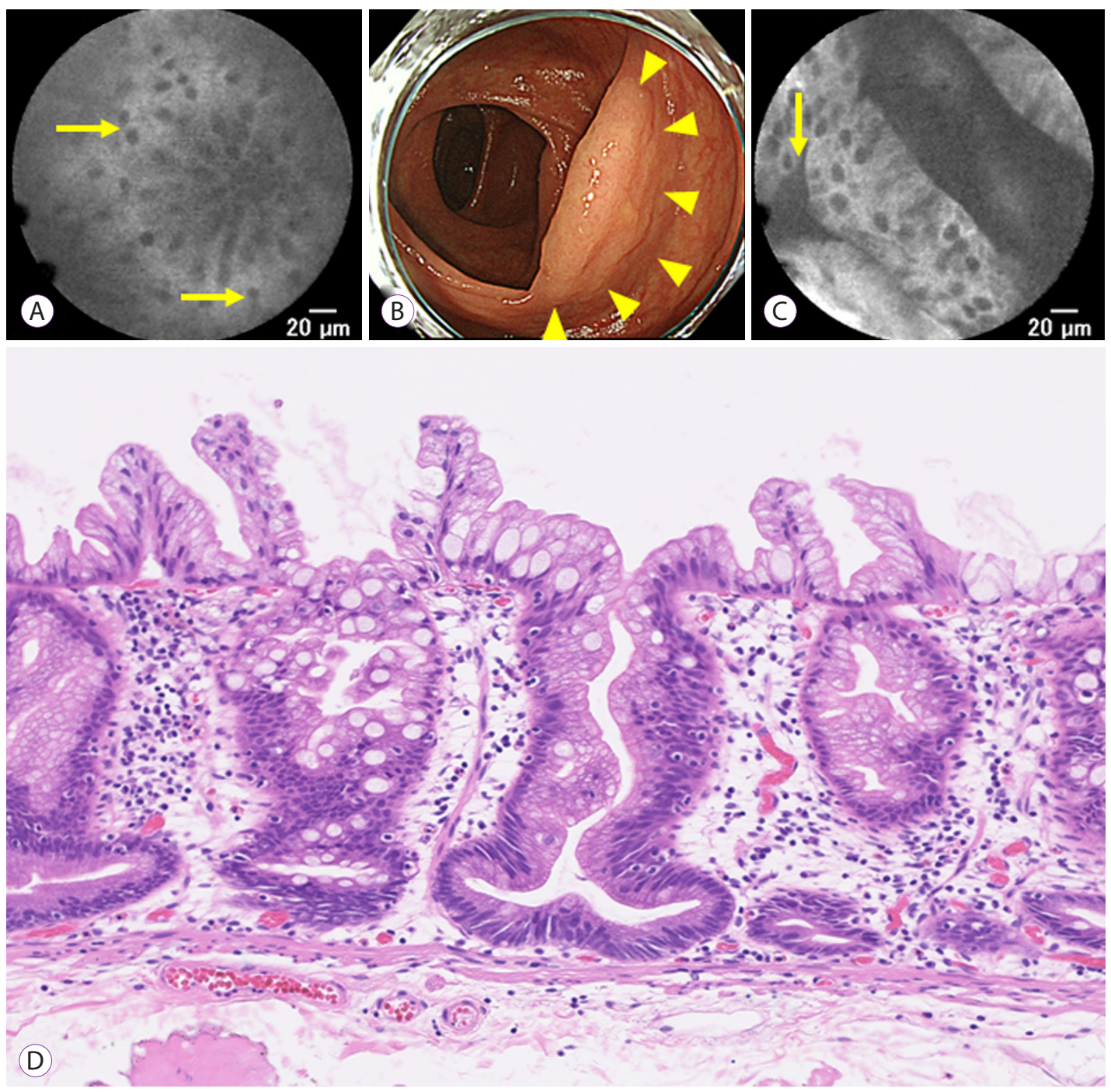

Fig. 3. A representative case of non-neoplastic colon mucosa and the colonic neoplasm observed with probe-based confocal laser endomicroscopy (pCLE) administrating $0.5 \mathrm{mg} / \mathrm{kg}$ of fluorescein. (A) Non-neoplastic colon mucosa observed with pCLE, dark goblet cells are seen (arrows), (B) sessile serrated lesion (SSL) located at the ascending colon with white light imaging, (C) SSL observed with pCLE, dilated crypts are seen (arrow), and (D) hematoxylin and eosin stain of the SSL.

endoscopic examination before pCLE. No fluorescein related adverse reactions were encountered in the present study except in one patient who developed yellowish urine with the level 4 dose of fluorescein.

In the literature, there is another study that investigated the optimal IV fluorescein dose for pCLE. Zhang et al. reported that $2 \mathrm{mg} / \mathrm{kg}$ of IV fluorescein was optimal for the observation of gastric intestinal metaplasia. ${ }^{19}$ In the present study, $0.5 \mathrm{mg} /$ $\mathrm{kg}$ of fluorescein was sufficient to visualize the tissue structure. The different results among studies could be explained by the fact that the target lesions in the present study were duodenal or colorectal mucosa, in which much less inflammation exists compared with GI metaplasia. It has been previously report- ed that inflammation in the bile duct caused by pre-stenting may interfere with the pCLE diagnosis. ${ }^{20}$ By comparing with cases without biliary inflammation, the accuracy of pCLE diagnosis for biliary stenosis was lower in cases with biliary inflammation. There is the possibility that inflammation caused by Helicobacter pylori infection may also interfere with the pCLE diagnosis. Shahid et al. investigated the optimal dose of fluorescein during pCLE for colon mucosa and concluded that $500 \mathrm{mg}$ of fluorescein may be optimal. ${ }^{21}$ They performed pCLE using several classes of $10 \%$ fluorescein dosage $(0.5 \mathrm{~mL}$, $1 \mathrm{~mL}, 2.5 \mathrm{~mL}, 5 \mathrm{~mL}, 7.5 \mathrm{~mL}$, and $10 \mathrm{~mL}$ ). In contrast, we used doses of fluorescein per $\mathrm{kg}$, which is more precise for each individual patient, in the present study. Although the optimal 
dose suggested in that study was higher than that of our study, the number of cases was small, and it is still difficult to make a robust conclusion at present. Nonaka et al. reported the usefulness of local fluorescein application during pCLE. ${ }^{22,23}$ They successfully obtained pCLE images by only several drops of $10 \%$ fluorescein using a catheter for dispersion. From their study, it was thought that only a small amount of fluorescein was satisfactory to conduct pCLE. Their report supports the result of the present study in that the dosage of fluorescein needed for pCLE is extremely low.

No serious adverse reactions related to the administration of IV fluorescein were experienced in the present study. Although it has been reported that the frequency of serious adverse reactions after IV fluorescein were low, ${ }^{8-10}$ the frequency of mild adverse reactions, including nausea, have been reported to be relatively high. ${ }^{11-13}$ The effectiveness of a reduced dose of IV fluorescein for specific patients has been reported by Xu et al. ${ }^{10}$ They reported that among 17 patients who had two repeated IV fluorescein angiography tests and an adverse reaction on the first IV fluorescein angiography test, the rate of adverse reactions on the second test was lower in patients who received a reduced dosage of IV fluorescein $(n=14)$ compared to those with the standard dosage $(n=3)(35.7 \%$ vs. $66.7 \%)$. Considering the relatively high rates of fluorescein related adverse reactions, a reduced or minimal dose of fluorescein may be an alternative and safe solution for patients. However, it may be difficult to avoid anaphylactic reaction as these may occur regardless of the dose of fluorescein.

As previously described, pCLE with local fluorescein application, rather than IV administration of fluorescein, has recently been reported. ${ }^{22,23}$ Although the use of local fluorescein application seems to be effective and safe, an investigation into the adverse reactions with a large number of cases has not been performed yet. Further studies are therefore necessary to investigate the safety of pCLE with local fluorescein application. Tashima et al. reported the effectiveness of dripping of food additives (curcumin and tartrazine) as an alternative fluorescent dye to examine a duodenal tumor ex vivo. ${ }^{24}$ In addition to the attempt to reduce the dose of IV fluorescein, a local application of fluorescent dye may become a solution for patients who have a severe allergy to fluorescein; however, the standard clinical use remains IV administration as fluorescein leakage from abnormal vessels cannot be identified with local fluorescein alone. Recent investigations have demonstrated that fluorescein leakage reflects microcirculatory disturbances and is considered to be an important finding to identify malignant lesions or inflammatory mucosa of ulcerative colitis. ${ }^{25-27}$

The present study has several limitations. Firstly, this is a pilot study and it is difficult to draw a solid conclusion; nevertheless, it highlights the potential dose reduction of IV fluorescein during pCLE. Secondly, the judgment of ID was subjective as off-line reviews were carried out by three endoscopists independently to ensure objectivity. Thirdly, in the present study we investigated the optimal dose of fluorescein only for duodenal and colorectal mucosa. Although bleeding in the target lesion usually disrupts the precise evaluation with NBI, pCLE can be performed regardless of bleeding. Correspondingly, the development of pCLE enables us to perform an optical biopsy of several other organs, including the esophagus, ${ }^{28}$ lung, ${ }^{29}$ biliary tract, ${ }^{30}$ pancreas, ${ }^{31}$ and urinary tract. ${ }^{32}$ The optimal dose of fluorescein for lesions with inflammation and in other organs may differ and these should be investigated individually. Furthermore, it is not clear whether sequential dynamic imaging using pCLE could be performed with a low dose of fluorescein.

In conclusion, in the present study, the use of a fluorescein iv dose of $0.5 \mathrm{mg} / \mathrm{kg}$ was feasible and sufficient to visualize the magnified structure of non-neoplastic duodenal or colorectal mucosa, as well as that of gastric HGD or CRNs, in Asian individuals.

Conflicts of Interest

The authors have no potential conflicts of interest.

Funding

This research was partly supported by AMED under Grant Number JP15ck0106028 and JP19ck0106375. This work was supported in part by The National Cancer Center Research and Development Fund 29-A-14.

Acknowledgments

We gratefully acknowledge the work of members of Center for Research Administration and Support in the National Cancer Center Hospital for designing the research plan. We are grateful to Dr. Victor Ciofoaia for carefully proofreading our manuscript.

\section{Author Contributions}

Conceptualization: Kazuya Inoki, Seiichiro Abe, Yutaka Saito

Data curation: KI, SA

Formal analysis: KI, SA

Funding acquisition: Hiroyuki Takamaru, YS

Writing-original draft: KI, SA

Writing-review\&editing: Yusaku Tanaka, Koji Yamamoto, Daisuke Hihara, Ryoji Ichijima, Yukihiro Nakatani, Hsin-Yu Chen, HT, Masau Sekiguchi, Masayoshi Yamada, Taku Sakamoto, Satoru Nonaka, Haruhisa Suzuki, Shigetaka Yoshinaga, Ichiro Oda, Takahisa Matsuda, YS

ORCID

$\begin{array}{ll}\text { Kazuya Inoki: } & \text { https://orcid.org/0000-0002-2703-9509 } \\ \text { Seiichiro Abe: } & \text { https://orcid.org/0000-0002-2736-6921 } \\ \text { Yusaku Tanaka: } & \text { https://orcid.org/0000-0001-6761-3571 } \\ \text { Koji Yamamoto: } & \text { https://orcid.org/0000-0002-1690-4165 } \\ \text { Daisuke Hihara: } & \text { https://orcid.org/0000-0002-3721-4892 } \\ \text { Ryoji Ichijima: } & \text { https://orcid.org/0000-0002-5977-3660 } \\ \text { Yukihiro Nakatani: } & \text { https://orcid.org/0000-0002-0524-2936 } \\ \text { Hsin-Yu Chen: } & \text { https://orcid.org/0000-0002-8332-4750 }\end{array}$


Hiroyuki Takamaru: Masau Sekiguchi:

Masayoshi Yamada: Taku Sakamoto: Satoru Nonaka:

Haruhisa Suzuki: Shigetaka Yoshinaga: Ichiro Oda:

Takahisa Matsuda: Yutaka Saito: https://orcid.org/0000-0002-7019-6331 https://orcid.org/0000-0001-6253-6896 https://orcid.org/0000-0003-3979-5560 https://orcid.org/0000-0002-0239-4977 https://orcid.org/0000-0002-0925-9137 https://orcid.org/0000-0003-2284-0943 https://orcid.org/0000-0002-2368-878X https://orcid.org/0000-0001-8666-127X https://orcid.org/0000-0002-9244-2820 https://orcid.org/0000-0003-2296-8373

\section{REFERENCES}

1. Wallace MB, Fockens P. Probe-based confocal laser endomicroscopy. Gastroenterology 2009;136:1509-1513.

2. Sharma P, Meining AR, Coron E, et al. Real-time increased detection of neoplastic tissue in Barrett's esophagus with probe-based confocal laser endomicroscopy: final results of an international multicenter, prospective, randomized, controlled trial. Gastrointest Endosc 2011;74:465-472.

3. Park JC, Park Y, Kim HK, et al. Probe-based confocal laser endomicroscopy in the margin delineation of early gastric cancer for endoscopic submucosal dissection. J Gastroenterol Hepatol 2017;32:1046-1054.

4. Kim B, Kim YH, Park SJ, et al. Probe-based confocal laser endomicroscopy for evaluating the submucosal invasion of colorectal neoplasms. Surg Endosc 2017;31:594-601.

5. Abe S, Saito Y, Oono Y, et al. Pilot study on probe-based confocal laser endomicroscopy for colorectal neoplasms: an initial experience in Japan. Int J Colorectal Dis 2018;33:1071-1078.

6. Buchner AM, Gomez V, Heckman MG, et al. The learning curve of in vivo probe-based confocal laser endomicroscopy for prediction of colorectal neoplasia. Gastrointest Endosc 2011;73:556-560.

7. Pittayanon R, Rerknimitr R, Wisedopas N, et al. The learning curve of gastric intestinal metaplasia interpretation on the images obtained by probe-based confocal laser endomicroscopy. Diagn Ther Endosc 2012;2012:278045

8. Wallace MB, Meining A, Canto MI, et al. The safety of intravenous fluorescein for confocal laser endomicroscopy in the gastrointestinal tract. Aliment Pharmacol Ther 2010;31:548-552.

9. Ha SO, Kim DY, Sohn CH, Lim KS. Anaphylaxis caused by intravenous fluorescein: clinical characteristics and review of literature. Intern Emerg Med 2014;9:325-330.

10. Xu K, Tzankova V, Li C, Sharma S. Intravenous fluorescein angiography-associated adverse reactions. Can J Ophthalmol 2016;51:321-325.

11. Marcus DF, Bovino JA, Williams D. Adverse reactions during intravenous fluorescein angiography. Arch Ophthalmol 1984;102:825.

12. Yannuzzi LA, Rohrer KT, Tindel LJ, et al. Fluorescein angiography complication survey. Ophthalmology 1986;93:611-617.

13. Lira RP, Oliveira CL, Marques MV, Silva AR, Pessoa Cde C. Adverse reactions of fluorescein angiography: a prospective study. Arq Bras Oftalmol 2007;70:615-618.

14. McLauchlan R, Waterman H, Waterman C, Hillier V, Dodd C. Ethnic variation in fluorescein angiography induced nausea and vomiting. Eye (Lond) 2001;15(Pt 2):159-162.

15. Keerl R, Weber RK, Draf W, Wienke A, Schaefer SD. Use of sodium fluorescein solution for detection of cerebrospinal fluid fistulas: an analysis of 420 administrations and reported complications in Europe and the United States. Laryngoscope 2004;114:266-272.

16. Dowlati A, Robertson K, Radivoyevitch T, et al. Novel phase I dose de-escalation design trial to determine the biological modulatory dose of the antiangiogenic agent SU5416. Clin Cancer Res 2005;11:79387944.

17. Sano Y, Tanaka S, Kudo SE, et al. Narrow-band imaging (NBI) magnifying endoscopic classification of colorectal tumors proposed by the Japan NBI expert team. Dig Endosc 2016;28:526-533.

18. Wallace M, Lauwers GY, Chen Y, et al. Miami classification for probebased confocal laser endomicroscopy. Endoscopy 2011;43:882-891.

19. Zhang YL, Bai L, Li Z, et al. A lower dose of fluorescein sodium is more suitable for confocal laser endomicroscopy: a feasibility study. Gastrointest Endosc 2016;84:917-923.e5.

20. Caillol F, Bories E, Poizat F, et al. Endomicroscopy in bile duct: inflammation interferes with pCLE applied in the bile duct: a prospective study of 54 patients. United European Gastroenterol J 2013;1:120-127.

21. Shahid MW, Crook JE, Meining A, et al. Exploring the optimal fluorescein dose in probe-based confocal laser endomicroscopy for colonic imaging. J Interv Gastroenterol 2011;1:166-171.

22. Nonaka K, Ohata K, Nakai Y. Probe-based confocal laser endomicroscopy of the duodenal mucosa with fluorescein dispersion. Dig Endosc 2014;26:604.

23. Nonaka K, Ohata K, Ban S, et al. Histopathological confirmation of similar intramucosal distribution of fluorescein in both intravenous administration and local mucosal application for probe-based confocal laser endomicroscopy of the normal stomach. World J Clin Cases 2015;3:993999.

24. Tashima T, Nonaka K, Ryozawa S, Tanisaka Y, Fujino T. Successful ex-vivo probe-based confocal laser endomicroscopy of a superficial nonampullary duodenal epithelial tumor with dripping of food additives: a case of tubular adenocarcinoma. VideoGIE 2019;4:128-130.

25. Meining A, Shah RJ, Slivka A, et al. Classification of probe-based confocal laser endomicroscopy findings in pancreaticobiliary strictures. Endoscopy 2012;44:251-257.

26. Spessotto P, Fornasarig M, Pivetta E, et al. Probe-based confocal laser endomicroscopy for in vivo evaluation of the tumor vasculature in gastric and rectal carcinomas. Sci Rep 2017;7:9819.

27. Tian Y, Zheng Y, Dong J, Zhang J, Wang H. Papaverine adjuvant therapy for microcirculatory disturbance in severe ulcerative colitis complicated with CMV infection: a case report. Clin J Gastroenterol 2019;12:407413.

28. Shah T, Lippman R, Kohli D, Mutha P, Solomon S, Zfass A. Accuracy of probe-based confocal laser endomicroscopy (pCLE) compared to random biopsies during endoscopic surveillance of Barrett's esophagus. Endosc Int Open 2018;6:E414-E420.

29. Wellikoff AS, Holladay RC, Downie GH, Chaudoir CS, Brandi L, Turbat-Herrera EA. Comparison of in vivo probe-based confocal laser endomicroscopy with histopathology in lung cancer: a move toward optical biopsy. Respirology 2015;20:967-974.

30. Caillol F, Bories E, Autret A, et al. Evaluation of pCLE in the bile duct: final results of EMID study: pCLE: impact in the management of bile duct strictures. Surg Endosc 2015;29:2661-2668.

31. Löhr JM, Lönnebro R, Stigliano S, et al. Outcome of probe-based confocal laser endomicroscopy (pCLE) during endoscopic retrograde cholangiopancreatography: a single-center prospective study in 45 patients. United European Gastroenterol J 2015;3:551-560.

32. Wu K, Liu JJ, Adams W, et al. Dynamic real-time microscopy of the urinary tract using confocal laser endomicroscopy. Urology 2011;78:225231. 